\title{
Teratogenic effect of the aqueous extract of the Foeniculum vulgare (fennel) on fetal development in mice
}

\author{
Maryam Shayan, ${ }^{a}$ Kobra Mehrannia, ${ }^{\mathrm{b}}$ Tayebeh Rastegar, ${ }^{\mathrm{b}}$ Maryam Khanehzad, ${ }_{1}^{\mathrm{b}}$ Taha Ghantabpour, \\ and Gholamreza Hassanzadehb,c
}

\author{
aStudent Research Committee, School of Medicine, Shahid Beheshti University of Medical Sciences, Tehran, Iran. \\ bDepartment of Anatomy, School of Medicine, Tehran University of Medical Sciences, Tehran, Iran. \\ 'Department of Neuroscience, School of Advanced Technologies in Medicine, Tehran University of Medical Sciences, Tehran, Iran. \\ Correspondence to Gholamreza Hassanzadeh (email: hassanzadeh@tums.ac.ir). \\ (Submitted: 12 August 2019 - Revised version received: 18 September 2019 - Accepted: 24 September 2019 - Published online: 26 October 2019)
}

\begin{abstract}
Objective The present study evaluated the effect of aqueous extract of Foeniculum vulgare on fetal development in pregnant mice models.

Methods A total number of 24 female BALB/c mice with a weight range of 25-30 g was divided into four groups. Each group received $0.25 \mathrm{ml}$ of the aqueous extract of $F$. vulgare with different concentrations $(2.5,12.5$, and $25 \mathrm{mg}$ ) and distilled water as a control group. The aqueous extract of $F$. vulgare administered through oral gavage on a daily basis from day 6 to day 15 of pregnancy. On day 16, the fetuses were analyzed in terms of morphological changes, skeletal disorders, and cellular alterations.

Results The result showed the dose-dependent teratogenic effect of the aqueous extract of $F$. vulgare. At 12.5 and 25 mg concentration, the teratogenic effect was more severe. Oral gavage administration of the aqueous extract of $F$. vulgare increased the number of dead fetuses and reduced the average weight, height, and crown-rump length. Subcutaneous hemorrhage, dorsal lesion, wrinkled skin, and considerably lower than normal fetal weight observed in gross morphological inspection at $25 \mathrm{mg}$ concentration. The skeletal studies revealed fetal anomalies, reduction in ossification and reduction in the number of ribs. Internal bleeding around the liver and lungs, pulmonary fibrosis and disruption in the arrangement of hepatocytes was also observed in histological analysis.

Conclusion Administration of the aqueous extract of $F$. vulgare results in embryotoxicity in mice models in morphological, skeletal and cellular levels.

Keywords Foeniculum vulgare, fennel, teratogenicity, embryotoxicity, fetal development, mice
\end{abstract}

\section{Introduction}

Congenital anomalies are described as defects that affect the developing fetus during gestation. These malformations can be identified in different prenatal stages through ultrasonography or may remain unidentified until birth or even later in infancy. Birth defects may result in abnormality of appearance, structure, organ functions and development. ${ }^{1}$ In September 2016 WHO reported that every year, 303,000 newborns die in the first 4 weeks after birth due to congenital anomalies. A child with congenital disorders has several limitations and is a huge burden on the families and health care systems. ${ }^{2}$

Although all of the congenital anomalies cannot be prevented, the environmental causes can be prevented by raising awareness of the mothers in societies. ${ }^{3}$ At the present time, the use of medicinal plants is increasing worldwide. As a consequence of expensive reproductive assistance methods and side effects of chemical medications, young couples tend to try medicinal herbs before visiting the specialist. ${ }^{4,5}$

Foeniculum vulgare, commonly known as fennel, is an aromatic herb grown in different Mediterranean regions and Western Europe. It is also cultivated in various parts of the world. F. vulgare is a perennial herb with yellow flowers and feathery leaves that falls within the family of Apiaceae. ${ }^{6}$ F. vulgare is called "Raziane" in Iranian traditional medicine and has been used in both medicine and food preparation since ancient times. Fennel has a sweet smell and it also tastes relatively sweet. Fennel seeds contain moisture, energy, sugars, essential oils, saturated fatty acids, essential and non-essential amino acids and different types of vitamins and minerals.?
Several medicinal applications of $F$. vulgare have been reported, e.g. antibacterial, anti-fungal, anti-oxidative, anti-carcinogenic, anti-inflammatory, anti-diabetic, antihypertensive, anti-stress and anxiety, anti-cough, memory enhancing, soothing indigestion, increasing in breast milk production, stimulation in menstrual flow, enhance in libido and facilitation in birth. ${ }^{7-13}$

Pregnant women may assume that consuming herbal medication is less harmful than chemical medication during pregnancy. Availability and inexpensiveness of herbs also play an important role in increasing the use of medicinal herbs. Safety and dosage of F. vulgare have not been studied during pregnancy and there is no data available about the teratogenicity of F. vulgare throughout gestation. Herbal medicine may interact in harmful ways with fetal development. Therefore, this study aims to discover whether the administration of various dosages of $F$. vulgare can cause a teratogenic effect on fetal development in animal models.

\section{Materials and Methods}

\section{Chemical and Agents}

The F. vulgare used in this study was purchased from the Pharmacognosy Department, School of Pharmacy, Tehran University of Medical Sciences, Tehran, Iran. F. vulgare seeds were milled with an electrical mill. The aqueous extract was prepared by dissolving $40 \mathrm{~g}$ of milled powder of F. vulgare 
seeds in $200 \mathrm{ml}$ distilled water. The mixture was refluxed for $2 \mathrm{~h}$. After reflux, the mixture was filtered with a large filter and then Büchner funnel. The filtered solution poured in Petri dish with $20 \mathrm{~cm}$ diameter and heated under $37^{\circ} \mathrm{C}$ temperature until dried. The dried extract was weighed and kept at $4^{\circ} \mathrm{C}$ in refrigerator until use. The extraction result of $40 \mathrm{~g}$ of milled powder of $F$. vulgare seeds was $6.67 \mathrm{~g}$ dried extract equivalent to $16.7 \%$. From the final aqueous extract three different dosages were prepared for oral gavage administration.

\section{Animals}

A total number of $24 \mathrm{BALB} / \mathrm{c}$ mice were used in this study (Razi Institute, Tehran, Iran). The mice utilized in this study were virgin adult females, weighing in the range of 25-30 g. All the animals were maintained in a controlled environment in terms of temperature $\left(23-25^{\circ} \mathrm{C}\right.$ ) and lighting (lights on from 08:00 AM to 08:00 PM) and had free access to food and water. All the operational guidelines in the housing, routine husbandry, handling, and experimental procedures were approved by the committee for animal ethics and experiments at the Tehran University of Medical Sciences.

Adult female mice mating occurred with fertile male mice in the same cages for the establishment of pregnancy. The mating success was monitored by checking the vaginal plugs. The presence of vaginal plugs was defined as day 0 of pregnancy.

\section{Experimental Design and Grouping}

The pregnant mice were caged separately and were randomly divided into four groups. On day 6 (beginning of gastrulation) of pregnancy, each group received a different dosage of aqueous extract of the $F$. vulgare through oral gavage administration on a daily basis for 9 days until day 15 of pregnancy (completion of organogenesis).

Group 1 (R1): animals received $0.25 \mathrm{ml}$ of aqueous extract of the $F$. vulgare with $2.5 \mathrm{mg}$ concentration.

Group 2 (R2): animals received $0.25 \mathrm{ml}$ of aqueous extract of the F. vulgare with $12.5 \mathrm{mg}$ concentration.

Group 3 (R3): animals received $0.25 \mathrm{ml}$ of aqueous extract of the $F$. vulgare with $25 \mathrm{mg}$ concentration.

Group 4 (CO): animals received $0.25 \mathrm{ml}$ of distilled water as a control group.

At the end of the experiments, on the $16^{\text {th }}$ day, mice were sacrificed by chloroform and the fetuses were removed.

\section{Morphological Study}

The fetuses were observed in terms of the total number of fetuses, number of live and dead fetuses, number of abortions, height, weight and crown-rump length (CRL). The fetuses were also investigated in terms of morphological and skeletal anomalies using a stereomicroscope.

\section{Histological Study}

The fetuses were placed in paraffin after fixation in Bouin's solution. After fixation, the samples underwent tissue staining with hematoxylin and eosin (H\&E). Then the samples were studied using a light microscope.

\section{Skeletal Study}

The fetuses were placed in acetone for $24 \mathrm{~h}$, then the skin was removed and fetuses were placed in a staining solution containing Alizarin Red-S, Alcian Blue, ethanol, and acetic acid. After that, the fetuses were stained through microwave radiation. For further clarification, the fetuses were placed in the solution containing $\mathrm{KOH} 1 \%$, ethanol $95 \%$, and glycerine for $24 \mathrm{~h}$. After these steps, fetuses were observed in terms of possible morphological and skeletal changes.

\section{Statistical Study}

Data were processed (GraphPad Prism 5.0 graphing and statistics software) by one-way ANOVA along with Dunnett's test or Turkey's multiple comparisons test. The $t$-test was performed for some data analysis. In all the experiments, $P<0.05$ was considered significant. Data are presented as mean \pm standard error of the mean (SEM).

\section{Results}

The effect of the aqueous extract of the F. vulgare in the morphological study shown the following results. The gestational factors differed significantly in R2 and R3 groups from those in the R1 and control groups. In comparison to R1 and control group, decreased number of live fetuses, increased number of dead fetuses, reduction in average weight, height and CRL were observed in R2 and R3 groups. Subcutaneous hemorrhage, wrinkling of the skin, dorsal lesions and considerably lower than normal fetal weight were observed in the R3 group with significant differences while compared with the $\mathrm{CO}$ group and other experimental groups. The morphological malformations on gross observation are summarized in Figs. 1 and 2.

Skeletal examination revealed a significant difference in skeletal malformation in the R3 group compared to R1, R2, and $\mathrm{CO}$ group. Fetal anomalies, reduction in ossification, reduction in the number of ribs and shortened ribs were observed in higher dosages of F. vulgare. Sternal nonunion, branched ribs, shortened fetal long bones, organ rotation abnormalities, and limb shortening were not observed in the fetuses. Figure 3 summarizes the results of the skeletal examination. Figure 4 shows the morphological malformations observed in mice fetuses. Figure 5 ( $\mathrm{a} \& \mathrm{~b}$ ) shows Alizarin Red-S and Alcian Blue staining of skeletal analysis.

The histological analysis showed internal bleeding in the liver and lungs in R2 and R3 groups. The bleeding was much higher in the R3 group. Disruption in the arrangement of hepatocytes and pulmonary fibrosis was also seen in R2 and R3 groups. Figure $5 \mathrm{c}$ and $5 \mathrm{~d}$ shows the hemorrhage in the liver and lungs.

To summarize the results, morphological, skeletal and histological analysis revealed the teratogenic effect of the aqueous extract of the F. vulgare in R3 $(25 \mathrm{mg})$ and R2 (12.5 mg) groups. Teratogenicity of $F$. vulgare is dose-dependent and is directly increased as the dose increments. No teratogenic effect was observed in the R1 group. Figure 6 demonstrated the experimental design and procedure of the present study.

\section{Discussion}

Foeniculum vulgare (fennel) is an herbal plant used widely in many countries because of its numerous applications. ${ }^{7}$ Fennel is known as a potent exogenous estrogen that can mimic the effect of estrogen in the body. The phytoestrogen in fennel's structure 

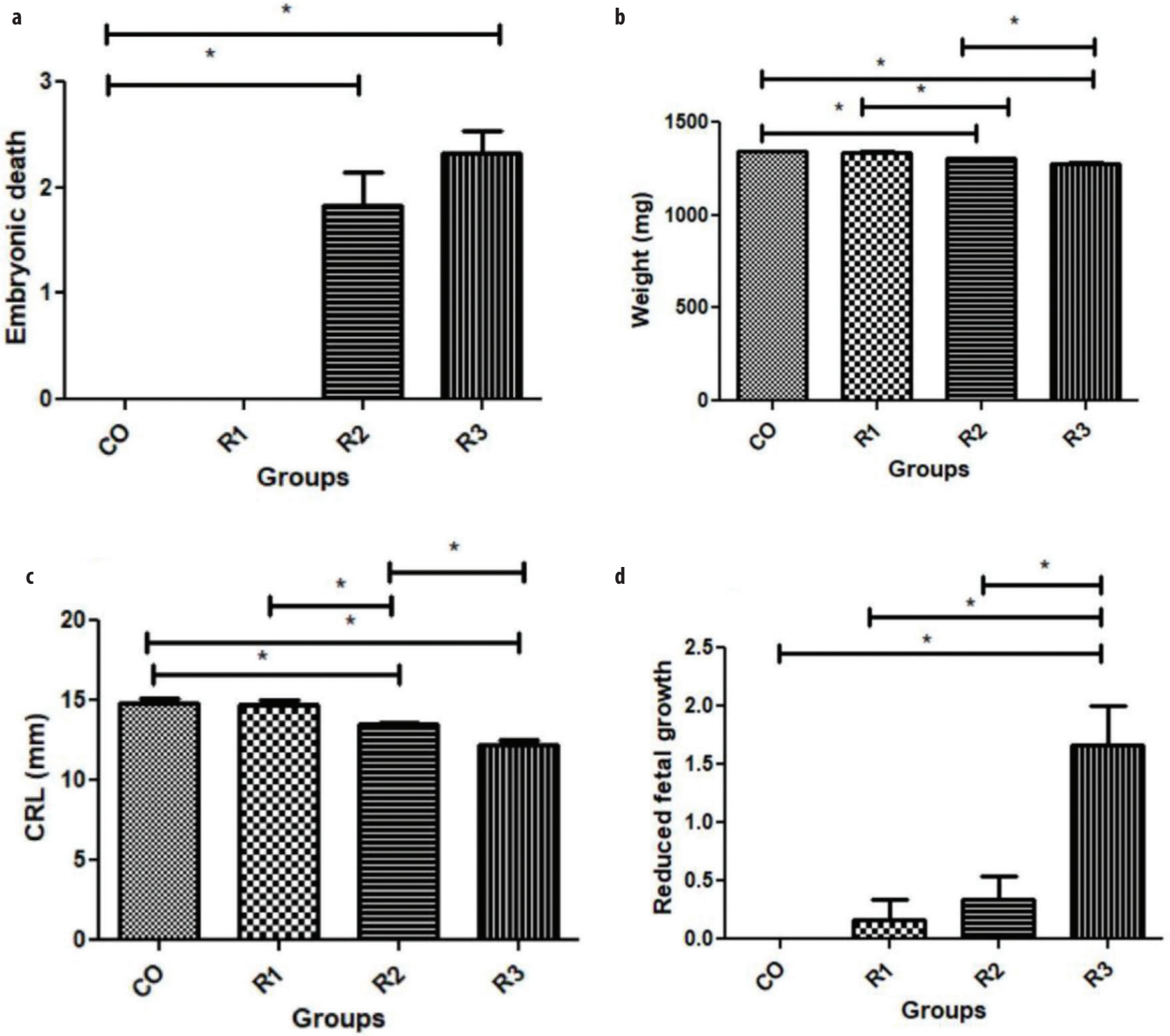

Fig. 1 (a) Number of dead fetuses in experimental groups was compared with the $\mathrm{CO}$ group. (b) Comparison of the weight of the fetuses in experimental groups with the $\mathrm{CO}$ group. Experimental groups are also compared with each other. (c) Differences between crownrump length (CRL) in experimental groups and the control group. (d) Comparison of the effect of Foeniculum vulgare on fetal growth in experimental groups versus control group. Data are expressed as mean \pm SEM. As it is shown in figure, ${ }^{*} P<0.05$ compared experimental group with the $\mathrm{CO}$ group and experimental groups to each other. Each group consists of six mice. The statistical analysis was carried out by one-way analysis of variance (ANOVA) followed by Turkey's post hoc test.
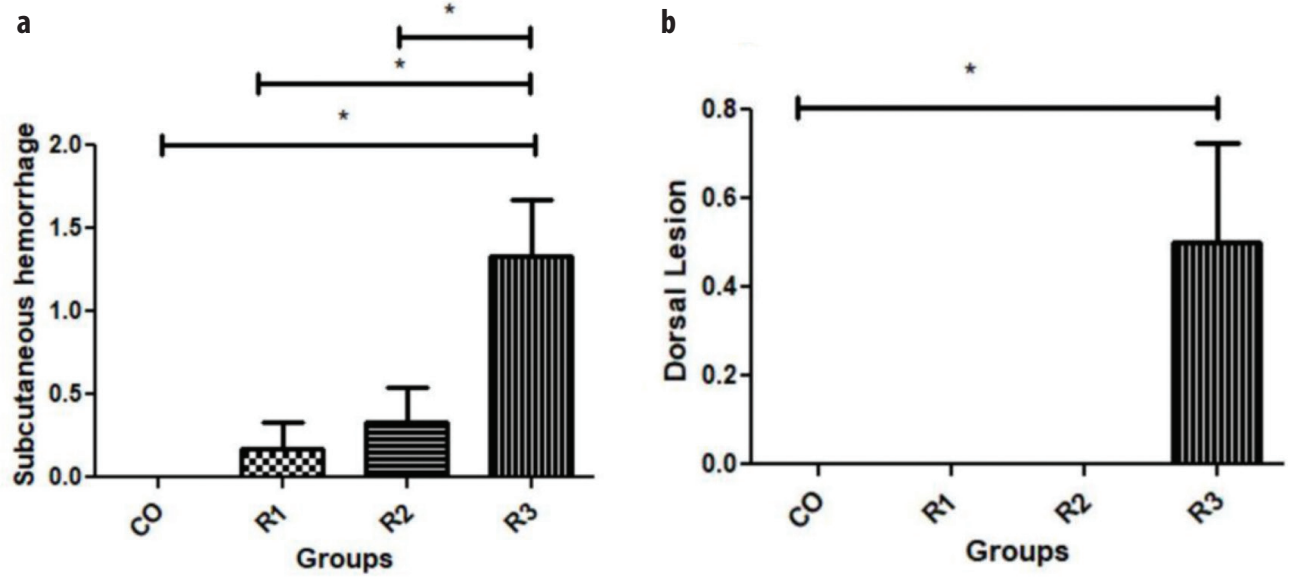

Fig. 2 Comparison of the effect of Foeniculum vulgare in causing subcutaneous hemorrhage (a) and dorsal lesions (b) during pregnancy in mice models. Data are expressed as mean \pm SEM. As it is shown in figure, ${ }^{*} \boldsymbol{P}<\mathbf{0 . 0 5}$ compared experimental group with the $\mathrm{CO}$ group and experimental groups to each other. Each group consists of six mice. The statistical analysis was carried out by one-way ANOVA followed by Turkey's post hoc test. 

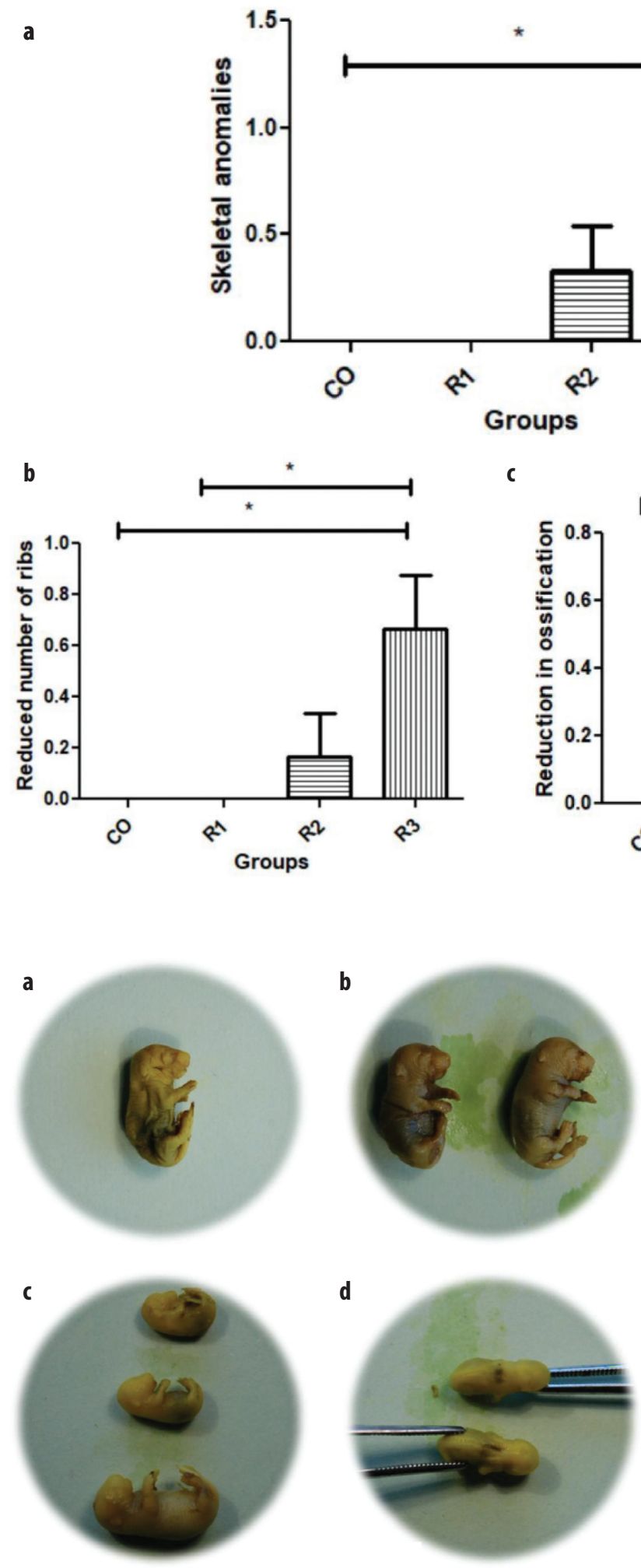

Fig. 4 (a) Wrinkled skin and subcutaneous bleeding in mice fetus at a concentration of $12.5 \mathrm{mg}$. (b) Severe subcutaneous hemorrhage and wrinkling of the skin at a concentration of $25 \mathrm{mg}$. (c) Fetal growth restriction and reduction in weight, height, and CRL of fetuses at concentrations of 12.5 and $25 \mathrm{mg}$. (d) Dorsal lesions at a concentration of $25 \mathrm{mg}$.

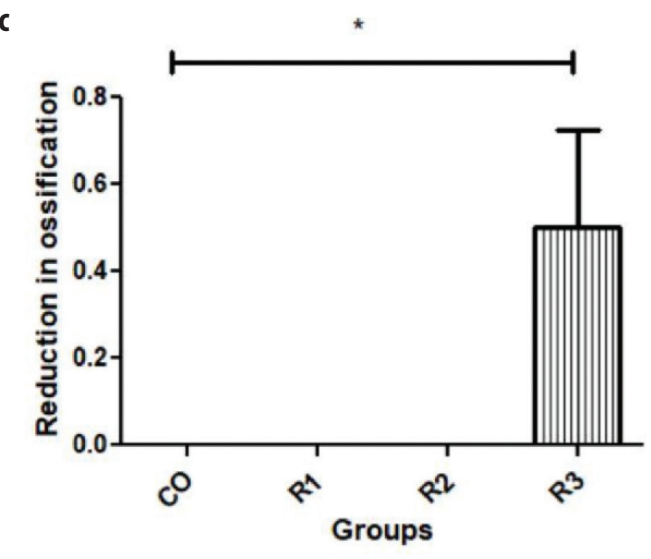

Fig. 3 (a) Comparison of the total number of observed skeletal anomalies in experimental groups with the $\mathrm{CO}$ group.

(b) Reduction in the number of ribs in experimental groups versus the $\mathrm{CO}$ group. (c) Reduction in the ossification centers in experimental groups was compared with the $\mathrm{CO}$ group. Data are expressed as mean $\pm S E M$. As it is shown in figure, ${ }^{*} P<0.05$ compared the experimental group with the $\mathrm{C} O$ group. Each group consists of six mice. The statistical analysis was carried out by one-way ANOVA followed by Turkey's post hoc test.
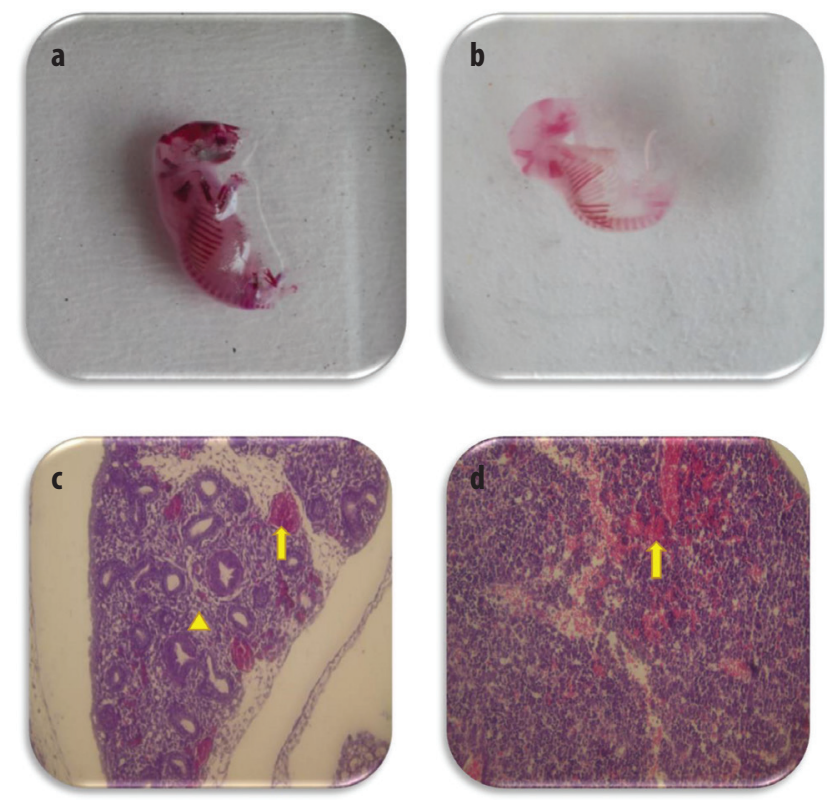

Fig. 5 (a) Shortened ribs at a concentration of $25 \mathrm{mg}$. (b) Reduction in the number of ribs at a concentration of $25 \mathrm{mg}$. The method of skeletal analysis was Alizarin Red-S and Alcian Blue staining. (c) Pulmonary hemorrhage (arrow) and fibrosis (arrowhead) at concentrations of 12.5 and $25 \mathrm{mg}$. (d) Disarrangement of hepatocytes and severe hepatic hemorrhage (arrow) at concentrations of 12.5 and $25 \mathrm{mg}$. H\&E staining was used in histological analysis. 


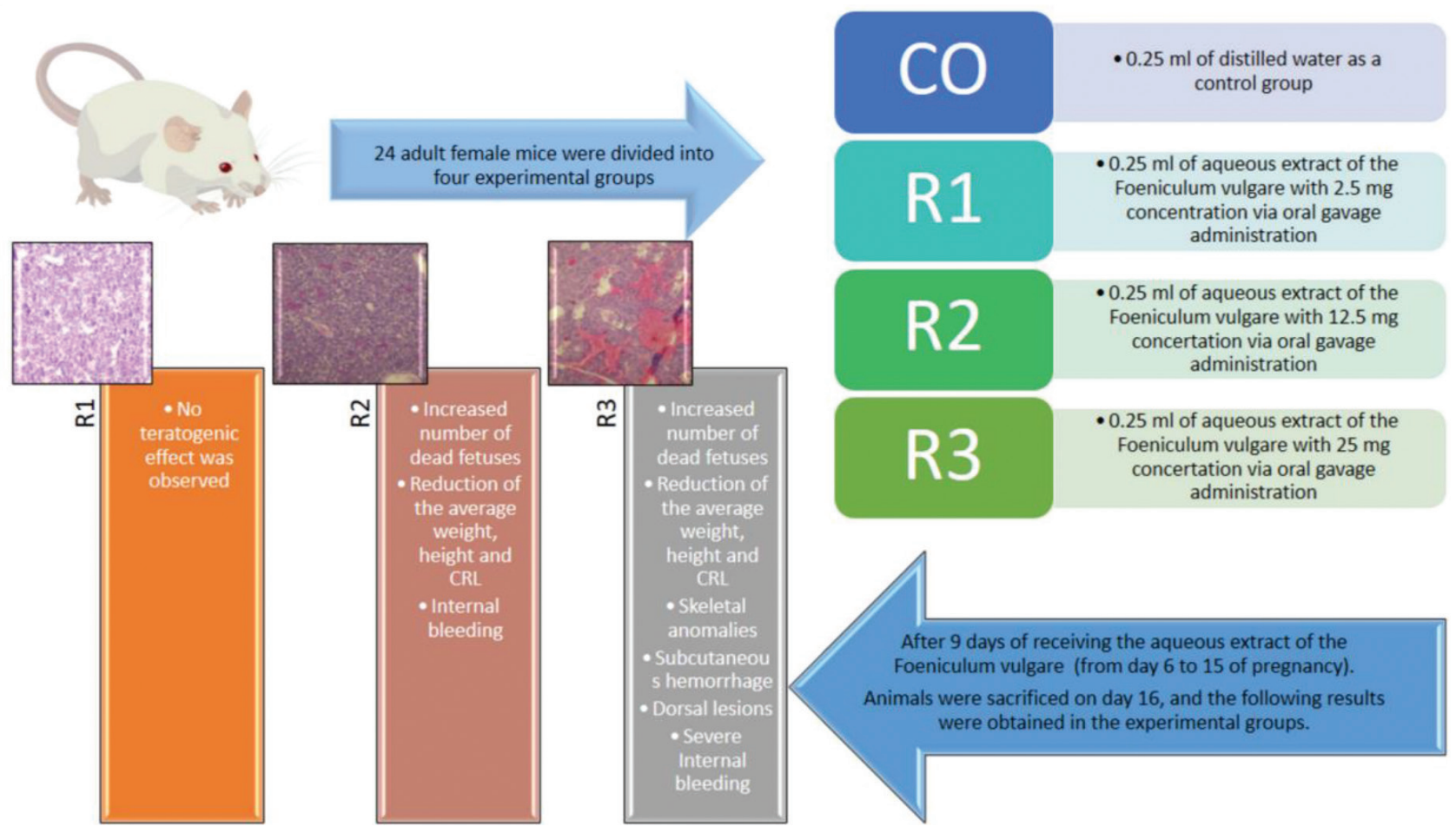

Fig. 6 Schematic representation of experimental design and procedure of the present study.

has an affinity to $\alpha$ and $\beta$ estrogen receptors. The number of authors has shown that fennel extract can increase the level of estrogen in serum hence it can be used as a treatment in adult women with polycystic ovary syndrome (PCOS), in addition, it can be used as an effective prescription to treat female infertility. ${ }^{14,15}$ It is also shown that fennel increases the number of graafian, antral and multilaminar follicles in mice ovary due to its estrogenic compound. ${ }^{5}$ Moreover, studies have shown that fennel can significantly decrease the toxicity of cyclophosphamide on the ovaries by increasing the level of estrogen and progesterone in serum. ${ }^{16}$ Fennel also showed a protective effect against misoprostol induced threatened abortion in mice models. ${ }^{17}$

To the best of our knowledge, this is the first study that evaluates the effect of aqueous extract of $F$. vulgare without any additional substances in pregnant animal models from day 6 (beginning of gastrulation) to day 15 (completion of organogenesis) of pregnancy.

In the present study, oral gavage administration of fennel at 12.5 and $25 \mathrm{mg}$ concentration caused an increased number of dead fetuses, reduction in weight, height, and CRL of fetuses. Besides severe anomalies in skeletal studies, e.g. reduction in ossification, reduction in the number of ribs, and shortening of the ribs were observed. Moreover, histological analysis revealed internal bleeding in the liver and lungs, disruption in the arrangement of hepatocytes and pulmonary fibrosis. Subcutaneous hemorrhage, wrinkling of the skin and dorsal lesions were also seen at $25 \mathrm{mg}$ concentration.

Anti-inflammatory and anti-oxidative effects of fennel are shown in several studies. ${ }^{14,18,19}$ Fennel can regulate the levels of liver enzymes in serum and prevent the intoxication effect of Cadmium in hepatic cells at a dose of $150 \mathrm{mg} / \mathrm{kg}$ in rats. ${ }^{20}$ Even though our findings showed that fennel extract at 12.5 and $25 \mathrm{mg}$ concentration can cause severe bleeding around the liver, along with disruption in arrangement of hepatocytes in mice fetuses. This result may be due to the reducing effect of fennel on liver enzymes. And also the differences in dose toxicity in mice and rats. Additionally, this study was conducted during pregnancy in mice, therefore, even the standard dosages can be teratogen during gestation.

Animal studies in the field of reproduction and infertility presented that fennel can regularize the level of estrogen, progesterone, and prolactin in serum, hence it can be used as a lowcost alternative therapy for infertility. ${ }^{5,14,15,20}$ Intraperitoneal administration at 100 and $200 \mathrm{mg} / \mathrm{kg}$ dosages in mice models resulted in significantly increasing the mentioned steroid hormones. ${ }^{15}$ Another study reported that intragastric administration at a $150 \mathrm{mg} / \mathrm{kg}$ dosage showed positive results in rat models of PCOS. In the study mentioned earlier, fennel showed both positive effects on renal function and on lowering the blood pressure. ${ }^{14}$ The estrogenic effect of fennel is due to trans-anethole and flavonoids ingredients that are found in this herbal plant. ${ }^{21,22}$ Although fennel showed a positive impact on improving fertility, this study proved that oral gavage administration of this herbal medication in mice models can cause severe anomalies and morphological disorders in fetuses. Therefore, it is best to avoid using this medicinal plant during gestation until complete evaluations in experimental studies.

The anethole component of fennel also revealed antithrombotic activity through the anti-platelet aggregation mechanism. ${ }^{23}$ It seems that the internal bleeding around the liver and lungs observed in this study may be the result of the antiplatelet activity of this herbal medicine.

In an animal study, the effect of intraperitoneal fennel injection along with misoprostol injection has been assessed. Hydroalcoholic extract of fennel at a $2.5,12.5$, and $25 \mathrm{mg} / \mathrm{kg}$ dosages were used in the study. Pretreatment with fennel showed a protective effect on misoprostol induced-abortion in day 6-15 of pregnancy in mice. ${ }^{17}$ Even though fennel showed positive outcomes on fetuses that have been threatened to abortion, the effect of fennel alone during gestation has not been 
evaluated in the above-mentioned study. In the presented study, it is shown that oral gavage administration of fennel alone has severe teratogenicity effect in mice embryos while using during day 6-15 of gestation in mice models. Since it has been proved that fennel can be used as a treatment in infertility and prevention of miscarriage, usage of this medicinal herb should be under the supervision of an expert in this field to determine the exact dosage and prevent the possible side effects. It is also recommended to avoid usage of fennel during pregnancy, particularly in the first trimester that organogenesis occurring.

\section{Conclusion}

The utilization of aqueous extract of $F$. vulgare at a concentration of 12.5 and $25 \mathrm{mg}$ results in embryotoxicity while orally administered in pregnant mice models. The embryotoxicity of this herbal medicine was observed in morphological, skeletal and cellular levels.

\section{Acknowledgment}

This study was part of a research grant supported by Tehran University of Medical Sciences, Tehran, Iran (Grant No: 98-02-30-43597).

\section{Conflicts of Interest}

None.

\section{References}

1. Connolly C, O'Donoghue K, O'Mahony M. PFM.54 a review of congenital anomalies in the Cork and Kerry region from 1996-2010. Arch Dis Childhood Fetal Neonatal Ed. 2014;99:A100.

2. Congenital anomalies [updated 2016]. Available from: https://www.who. int/news-room/factsheets/detail/congenital-anomalies

3. Sarmah S, Muralidharan P, Marrs JA. Common congenital anomalies: environmental causes and prevention with folic acid containing multivitamins. Birth Defects Res C Embryo Today 2016;108:274-286.

4. Minas A, Najafi G, Jalali AS, Razi M. Fennel induces cytotoxic effects against testicular germ cells in mice; evidences for suppressed pre-implantation embryo development. Environ Toxicol. 2018.

5. Khazaei M, Montaseri A, Khazaei MR, Khanahmadi M. Study of Foeniculum vulgare effect on folliculogenesis in female mice. Int J Fertil Steril. 2011:5:122-127

6. Kooti W, Ali-Akbari S, Sharafi-Ahvazi N, Asadi-Samani M, Ashtary-Larky D, Moradi M. Therapeutic and pharmacological potential of Foeniculum vulgare Mill: a review. J HerbMed Pharmacol. 2015;4:1-9.

7. Badgujar SB, Patel VV, Bandivdekar AH. Foeniculum vulgare Mill: a review of its botany, phytochemistry, pharmacology, contemporary application, and toxicology. Biomed Res Int. 2014;2014:842674

8. Mesfin M, Asres K, Shibeshi W. Evaluation of anxiolytic activity of the essential oil of the aerial part of Foeniculum vulgare Miller in mice. BMC Complement Altern Med. 2014;14:310.

9. Kacaniova M, Mellen M, Vukovic NL, Kluz M, Puchalski C, Haščík P, et al. Combined effect of vacuum packaging, fennel and savory essential oil treatment on the quality of chicken thighs. Microorganisms. 2019;7. pii: E134.

10. Juárez-Vázquez Mdel C, Carranza-Álvarez C, Alonso-Castro AJ, GonzálezAlcaraz VF, Bravo-Acevedo E, Chamarro-Tinajero FJ, et al. Ethnobotany of medicinal plants used in Xalpatlahuac, Guerrero, Mexico. J Ethnopharmacol. 2013:148:521-527.

11. Javidnia K, Dastgheib L, Mohammadi Samani S, Nasiri A. Antihirsutism activity of Fennel (fruits of Foeniculum vulgare) extract. A double-blind placebo controlled study. Phytomedicine. 2003;10:455-458.

12. Joshi H, Parle M. Cholinergic basis of memory-strengthening effect of Foeniculum vulgare Linn. J Med Food. 2006;9:413-417.
13. El-Soud N, El-Laithy N, El-Saeed G, Wahby MS, Khalil M, Morsy F, et al. Antidiabetic activities of Foeniculum vulgare Mill. Essential oil in streptozotocin-induced diabetic rats. Maced J Med Sci. 2011;4:139-146.

14. Sadrefozalayi S, Farokhi F. Effect of the aqueous extract of Foeniculum vulgare (fennel) on the kidney in experimental PCOS female rats. Avicenna J Phytomed. 2014:4:110-117.

15. Sadeghpour N, Khaki AF, Najafpour A, Dolatkhah H, Montaseri A. Study of Foeniculum vulgare (Fennel) seed extract effects on serum level of estrogen, progesterone and prolactin in mouse. Crescent J Med Biol Sci. 2015;2:23-27.

16. Hassanpour A, Yousefian S, Askaripour M, Sharififar F, Ezzatabadipour M. Ovarian protection in cyclophosphamide-treated mice by fennel. Toxicol Rep. 2017:4:160-164.

17. Shokrzadeh M, Dashti A, Aghajanshakeri S, Pourabbas B, Ghassemi Barghi N, Ogunkunle ATJ, et al. Prevention effects of Foeniculum vulgare (Fennel) hydroalcoholic extract for threatened abortion by misoprostol induction in experimental mice. Int J Trad Nat Med. 2019;9:1-16.

18. Choi EM, Hwang JK. Antiinflammatory, analgesic and antioxidant activities of the fruit of Foeniculum vulgare. Fitoterapia. 2004;75:557-565.

19. Oktay M, Gülçin İ, Küfrevioğlu Öl. Determination of in vitro antioxidant activity of fennel (Foeniculum vulgare) seed extracts. LWT - Food Sci Technol. 2003;36:263-271

20. Abdel-Wahab A, Hashem Abdel-Razik AR, Abdel Aziz RL. Rescue effects of aqueous seed extracts of Foeniculum vulgare and Carum carvi against cadmium-induced hepatic, renal and gonadal damage in female albino rats. Asian Pac J Trop Med. 2017;10:1123-1133.

21. Price KR, Fenwick GR. Naturally occurring oestrogens in foods - a review. Food Addit Contam. 1985;2:73-106.

22. Zhang S, Chen X, Devshilt I, Yun Q, Huang C, An L, et al. Fennel main constituent, trans-anethole treatment against LPS-induced acute lung injury by regulation of Th17/Treg function. Mol Med Rep. 2018;18: 1369-1376.

23. Tognolini M, Ballabeni V, Bertoni S, Bruni R, Impicciatore M, Barocelli E. Protective effect of Foeniculum vulgare essential oil and anethole in an experimental model of thrombosis. Pharmacol Res. 2007;56:254-260.

This work is licensed under a Creative Commons Attribution-NonCommercial 3.0 Unported License which allows users to read, copy, distribute and make derivative works for non-commercial purposes from the material, as long as the author of the original work is cited properly. 